\title{
The Effective Ways to Promote Teaching Supervision of the Affiliated Colleges in Universities
}

\author{
Wenjing Sun \\ Zaozhuang University \\ Zaozhuang, China
}

\begin{abstract}
Teaching supervision in affiliated colleges is an important part in the teaching quality monitoring system. With the strengthening of the management of affiliated colleges, the effectiveness of teaching supervision should be further promoted. This paper analyzes the meaning and importance of the existence of teaching supervision elaborately, and then through the research and analysis on problems of teaching supervision, the paper reveals the current problems. Finally, focusing on the current situation of teaching supervision, the paper proposes and constructs some corresponding countermeasures.
\end{abstract}

Keywords-teaching supervision; affiliated college; teaching quality

\section{INTRODUCTION}

The quality of teaching is the foundation of all universities. Teaching supervision is one of the important guarantees to strengthen teaching management and improve teaching quality in colleges and universities. The organization of teaching supervision has been established in many affiliated colleges for many years. It has played an important role in teaching and has accumulated a lot of useful experience, but there are also many problems that need to solve and carefully pay reflection on. For example: leaders and teachers in affiliated colleges do not know enough about the role and location of teaching supervisors; The supervision system is not perfect enough; The supervision team's specialization is not high, the content of the work is shallow and the way of work is simple; There is no special funding guarantee for supervisors; Supervision is more than guidance; There is a gap between the actual needs of college supervision, and so forth. These problems affect the effectiveness of teaching supervision in affiliated colleges. This paper analyzes the existing problems of teaching supervision of affiliated colleges in universities and makes preliminary exploration on the way to improve the effectiveness of teaching supervision.

\section{THE MEANING OF TEACHING SUPERVISION}

Some researchers have pointed out: "Teaching supervision refers to the supervision, evaluation, inspection, and guidance of the teaching work of the university based on the organizational structure of the university and based on fixed working principles, procedures, and methods. It is an independent teaching quality assurance behavior carried out by universities.'[1] We also recognize the importance of teaching supervision in colleges and universities: it is the demand for the popularization of higher education and the monitoring of teaching quality, and it is the need to establish a monitoring system that closely complements the decisionmaking and implementation systems of universities. It is also a need to strengthen the communication between teaching management, teachers, and students.

What is a teaching supervision? Scholars have always been controversial about the definition of its connotation. Some people compare it with education supervision, and think that teaching is a form of education. Teaching supervision belongs to the scope of supervision and guidance adopted by the management department on school teaching activities. Some people think of it as: "a school's internal supervision system and think that it belongs to the internal supervision of the school is a series of measures taken by the school to ensure the quality of teaching, supervision, guidance, and evaluation of teaching activities.'[2] It should be considered as a regulatory measure aimed at ensuring its quality. Some people also define teaching supervision from a functional point of view. According to the scientific theory of education, teaching supervision supervises, evaluates, and inspects teaching work, and adopts effective methods and means to promote win-win results and quality of teaching. Some scholars believe that "Although these definitions are different in angle, the purpose of implementing teaching supervision is the same, that is, to improve the quality of teaching."[3] Because there are no regulations related to teaching supervision in China, it is impossible to clearly define the concept. The theoretical research foundation is also relatively weak, but in many theoretical discussions. The author believes that the more accurate expression is: "Teaching supervision is granted by institutions of higher learning and corresponding institutions are established. Its members implement the inspection, supervision, and evaluation of teaching activities shall be obliged to objectively report to the leading departments at higher levels information such as teaching conditions and quality, and put forward suggestions for teaching improvement."[2]

\section{PROBLEMS IN TEACHING SUPERVISION OF AFFILIATED COLLEGES IN UNIVERSITIES}

First of all, teaching supervision mechanism pays more attention to supervise teachers' teaching than students' 
learning. In the implementation of teaching supervision, the emphasis of supervision is often placed on supervising teachers' teaching, rarely on learning of students. This kind of emphasis on "teaching" makes the content of teaching supervision missing and deviates from the service subject of the school.

Furthermore, teaching supervision mechanism pays more attention to supervision than guidance. In the implementation process, supervisors are often focusing on supervision, inspection and evaluation, and little specific guidance is provided on problems in teaching, learning and teaching management. This phenomenon of "more supervision and less guidance" has increased the distance between supervisors and supervised personnel and weakened the quality and effectiveness of supervision.

What's more, in terms of the composition of the supervisory team, only the quantity is valued and the quality is not valued. In the course of building a teaching supervision team, it has taken into account the relations between various functional departments. It has a large number of old and weak personnel and it is not very responsible for teachers who are not very good at business skills. It has failed to effectively improve their supervision level. The quality of teaching supervision is difficult to guarantee.

In addition, in the process of evaluation, teaching supervision often uses single evaluation and rarely implements multiple evaluations. This phenomenon, ignoring the function of teaching supervision and evaluation, frustrated the enthusiasm of teachers, students and teaching managers.

Last but not least, in the course of implementation, teaching supervision relies more on supervision materials of teaching supervisors to evaluate the subjects under supervision, and does not fully develop the Democratic style of work, relying on teachers, students, and teaching administrators to obtain extensive teaching information. This affects the authenticity and reliability of the supervision work.

In view of the above problems in the implementation of teaching supervision, the author puts forward some suggestions to promote teaching supervision of the affiliated colleges in universities.

\section{The EFFective Ways to Promote Teaching SUPERVISION OF THE AFFILIATED COLLEGES IN UNIVERSITIES}

\section{A. Establishing the Concept of Teaching Supervision}

The people-oriented teaching supervision is to change the supervision function from supervision, inspection and evaluation to guidance and guidance. Lu carries out positive evaluation, developmental evaluation and process evaluation in teaching evaluation. In the process of supervision, equal treatment, with the method of discussion, the spirit of learning, so that the subject of supervision to accept the views with sincerity. Teaching supervision must have the concept of "management is the task", with the goal of promoting the improvement of teaching quality, providing advisory services for the school's teaching management work decisions, and providing communication and communication services between supervisors and supervised objects. In the teaching supervision system, we should base on the principle of "fair, fair, open, scientific, and Democratic" supervision and evaluation.

\section{B. Improving the Function and Duty of Teaching Supervision}

Teaching supervision is a very important part of the quality control system of teaching management in universities. At present, universities, society, and students are paying great attention to the quality of teachers and their' teaching. It will undoubtedly be beneficial for the supervision function to be put into better play to update the concept of teaching supervision, redefine the functions and responsibilities of teaching supervision, and adjust the regular functions of existing supervision work.

In recently, the regular duties of teaching supervisors in affiliated colleges mainly include random listening, checking classes, checking teaching orders, conducting teaching evaluation, supervising the implementation of practical courses, surveying teachers and students' opinions on teaching, and checking examination papers, and so forth. In general, their main role is to monitor the quality of studying and teaching. The traditional supervision system has played a certain role in guiding and promoting the improvement of the teaching level of young teachers and the improvement of the quality of personnel training. However, in general, the supervision is more than guidance. How to make the supervision play a better role in promoting teachers, especially young teachers' teaching level? How to improve students' learning attitude and learning atmosphere so as to improve the teaching quality effectively? How to make the supervision work more in line with the actual work of the college and the actual needs of teachers' and students'? This requires the affiliated college to re-position the functions and responsibilities of the teaching supervision according to the actual work of the college.

First, we should strengthen the developmental function of supervision. The orientation of the secondary college supervision and the school-level supervision should have their own emphasis. In addition to supervision and inspection, the duty of supervision at the affiliated colleges should focus on guidance. The supervision should be people-oriented, actively communicate with teachers and students, and place one of the focuses on guiding and guiding the growth of teachers, especially young teachers, in order to promote the professional development of young teachers and improve the teaching level of teachers. The basic purpose is to influence and guide the teachers from the teaching body, the teachers, to give full play to their potential, and to inspire and guide the teachers' self-growth, especially the growth of young teachers. Only by placing equal emphasis on "supervision" and "guidance" can we truly establish a second-level supervision mechanism with the professional development of teachers and the overall improvement of teacher quality as 
the core, so that the supervision mechanism can better play its role in guiding and improving teachers.

Second, in addition to supervising teachers, we must also supervise students' learning. At present, the supervision work is mainly aimed at the expansion of teachers' teaching behavior. Little attention is paid to the learning situation of students, which is the mainly part of learning. Even if it is involved, the contents involved are mostly limited to the general judgment of the overall situation or the statistics of the number. For example, students' overall learning status, and attendance, etc.. As for whether students can be guided and attracted by teachers, actively participate in classroom teaching, and whether students can truly be promoted and enlightened through learning, there is a lack of in-depth and scientific investigation and measurement. Students are the object of teaching. Students' learning situation and students' harvest directly reflect the quality of teaching in schools and teachers. Therefore, the supervision of teachers should pay equal attention to the supervision of students. The supervision of affiliated colleges on the front line of teaching should strengthen the concept of supervision, strengthen the supervision function of supervision, and guide teachers to pay more attention to the learning needs of students. At the same time, the supervision directly leads the students' learning in the process of supervision, and promptly understands, controls, and feedback the students' learning conditions. It will promote the teaching work of teachers from another perspective, promote the quality of students 'learning, and improve the style of learning.

\section{Strengthening the Professional Construction of Teaching Supervision Teams}

The purpose of the supervision work of the affiliated college is the teaching work of the college. The supervision work has the characteristics of concretion and specialization. This determines the requirements for the professional structure of the supervision team and the quality of the supervision personnel. The teaching supervision of the second level college should not only have rich teaching experience and teaching management experience, but also understand professional knowledge. It must not only have high academic accomplishments, but also have the ability to study teaching, guide teachers' teaching, and personality affinity. In this way, supervision can be effectively carried out.

At present, the construction of the supervisory team of the second-level colleges in the school is uneven, and there are certain differences in terms of professionalism, ratio of academic personnel to management personnel, age structure and quality of personnel. In addition, some are basically employed teachers, and some are completely retired experts, which is not conducive to the guarantee of time and a reasonable division of labor; Some have a large number of people and others have a small number, which is not conducive to conducting in-depth discussions within a certain range, and is not conducive to the science, fairness, and objectivity of evaluation.
To strengthen the construction of the supervisory team of the affiliated college, it is necessary to establish a formal evaluation and recruitment mechanism, clearly supervise the selection criteria, establish a combination of full-time and part-time jobs suitable for the affiliated college, and focus on full-time supervision. The teaching supervision team is formed according to different disciplines and majors to ensure the rationality of the supervision professional knowledge structure. While considering professionalism, consideration should be given to personnel with managerial experience in the supervisory team, or personnel with both academic and managerial capabilities, to ensure that the supervisory team has strong organizational management and coordination capabilities. The age structure should be balanced and consider whether there is enough time and energy to ensure the supervision and whether it can adapt to the needs of knowledge renewal; the number of persons should also be specified to ensure the objectivity of the evaluation. To strengthen the specialized construction of teaching supervision in secondary colleges, it is necessary to complement each other's advantages and strengthen the communication of supervisory work between affiliated colleges and universities. The education administration departments at the school level or above shall organize, Liaise with, establish inter-affiliated colleges, inter-school, and cross-regional teaching supervision academic organizations, regularly exchange supervisory experience, and explore and disseminate advanced experience and practices in teaching supervision. Guide and promote the supervision work to keep pace with the times, and further integrate the teaching practice, to become professional and expert. In addition, at present, there is no special funding guarantee for the supervision and treatment of the secondlevel colleges. The use of funds is not decided by the supervision team, which affects the active and independent development of the supervision team's work and also affects the multi-directional communication of supervision work.

\section{The Innovation of Supervision in Work Forms and Methods}

The traditional supervision work of the secondary college is mainly organized and managed at the college level, and mainly performs supervision, inspection, and evaluation functions. Under the new circumstances, if teaching supervision is to better play its new functions and responsibilities, it must be guided by the modern concept of education, teaching and evaluation, put people first, correctly handle the relationship between supervision and guidance, and strengthen the functions of guidance, assistance and development. Change the traditional supervision methods, and carry out work independently and innovator.

To carry out the supervision work effectively, the supervision group should change from passive to active. The supervision group should take the initiative to go deep into the teachers and students, to go deep into the teaching and research room, to listen to the voices of teachers and students and go into the teaching and research room to understand the overall situation and the needs of teachers and students, and the problems that needs to be urgently solved. The teaching 
and research office is the management organization of the teaching front line. The supervisor of the Institute should go deep into the teaching and research office and work with the teaching and research office to make suggestions on the key work of the teaching and research office at a certain stage and the teaching problems that need to be solved urgently. Combining regular supervision with special supervision and adopting flexible methods and methods to carry out supervision work will certainly enhance the pertinence and effectiveness of the work and enable the supervision work to be carried out vigorously.

In supervision, we must overcome the comprehensive, broad and general supervision methods. We must focus on specific topics, focus on them, and combine them with practical research. On the basis of the alignment, it is possible to carry out special supervision work on a certain issue, a certain profession, a certain class, a certain course, and a certain teacher. For young teachers with insufficient teaching experience, model class supervision and lecture supervision can be carried out. For teachers with teaching problems, diagnostic supervision and guidance supervision can be carried out; a discussion approach could be developed to address issues of a general or controversial nature; for those who need to track and observe for a long time, they can use tracking supervision.

\section{CONCLUSION}

In short, the sustainable development of the teaching supervision in the affiliated college cannot be separated from the reform and innovation of the supervision work. We will constantly improve the supervision mechanism, make new efforts to locate the functions and responsibilities of teaching supervision in secondary colleges, and strengthen the developmental functions and supervision functions of supervision. Further strengthen the teaching supervision team specialization, expert construction; enriching the supervision work form and innovating the supervision method; provide more space for supervisors to work autonomously; it will definitely inspire the supervision work of the second level college to continue to rejuvenate, and the harmony of the world play an important role.

\section{REFERENCES}

[1] Gordon Robert M, Wang Xiubing, Tune Jane. Comparing Psychodynamic Teaching,Supervision, and Psychotherapy Over Videoconferencing Technology with Chinese Students[J].Psychodynamic psychiatry, 2015, (04).

[2] Lynn Mc Alpine. How do post-Ph.D.Scientists locate teaching and supervision within their academic practice[J].Teaching in Higher Education, 2014, (08).

[3] Lorraine Dwkruyf and Dale-elizabeth Pehrsson.School Counseling Site Superbisor Traing: An Exploratory Study[J].Counselor Education and Supervision, 2011.

[4] Yan Chen, Yin Tang.Discussion on Construction and Development of Local Higher Vocational Colleges'Teaching Supervision[J]. Physics. 